\title{
Perceived affordances and constraints regarding instructors' use of Peer Instruction: Implications for promoting instructional change
}

\author{
Chandra Turpen, ${ }^{1}$ Melissa Dancy, ${ }^{2}$ and Charles Henderson ${ }^{3}$ \\ ${ }^{1}$ Department of Physics, University of Maryland-College Park, College Park, Maryland 20782, USA \\ ${ }^{2}$ Department of Physics, University of Colorado-Boulder, Boulder, Colorado 80309, USA \\ ${ }^{3}$ Department of Physics and Mallinson Institute for Science Education, Western Michigan University, \\ Kalamazoo, Michigan 49008, USA \\ (Received 3 December 2014; published 22 February 2016)
}

\begin{abstract}
[This paper is part of the Focused Collection on Preparing and Supporting University Physics Educators.] In order to promote sustained and impactful educational transformation, it is essential for change agents to understand more about faculty perceptions associated with either adopting or not adopting a research-based instructional strategy (RBIS). In this paper, we use interviews with 35 physics faculty to examine barriers and affordances to the use of the research-based instructional strategy of Peer Instruction. We found that the most common reasons faculty give for aligning their instruction with Peer Instruction is that it is not lecture and they have had positive experiences with Peer Instruction. The most common reasons faculty give for not using Peer Instruction are concerns about the time it will take, the loss of content coverage, and having had bad experiences with it. Additionally, we found the perceived barriers to be very different depending on whether the interviewee was a user of Peer Instruction or not, with nonusers being more concerned with time and users being more concerned with implementation difficulties. It is important for change agents to understand and address concerns faculty have about implementing researchbased instructional strategies. Based on these results we offer four recommendations for those interested in promoting educational transformation toward research-based instructional strategies: (1) do not waste a lot of time criticizing lecture-based instruction and convincing faculty of the value of research-based strategies (they are already dissatisfied with lecture), (2) understand and address concerns faculty have about implementing active learning techniques, (3) focus on supporting and encouraging faculty experiences with RBIS, (4) address concerns faculty new to RBIS have about the time and energy needed to change.
\end{abstract}

DOI: 10.1103/PhysRevPhysEducRes.12.010116

\section{INTRODUCTION}

One of the important ways that the field of physics education research (PER) seeks to improve undergraduate instruction is via the development and dissemination of research-based instructional strategies (RBIS). Prior research suggests that while most faculty are aware of many of these RBIS, faculty often make little to no use of them [1]. Further, we know that many faculty who begin using a RBIS discontinue use [1]. Thus, it is important to better understand faculty decision making regarding the use of RBIS as well as faculty perceptions of RBIS prior to and during implementation.

In this paper, we examine faculty self-reported perceptions of the RBIS of Peer Instruction (PI) [2-6]. By understanding more about the reasons faculty report for either using or not using this very common RBIS, we hope to provide insights to inform more impactful efforts by

Published by the American Physical Society under the terms of the Creative Commons Attribution 3.0 License. Further distribution of this work must maintain attribution to the author $(s)$ and the published article's title, journal citation, and DOI. change agents. Semistructured interviews with 35 faculty members familiar with Peer Instruction were used to answer the following research questions:

(1) What reasons do instructors give for aligning their instruction with Peer Instruction?

(2) What reasons do instructors give for not aligning their instruction with Peer Instruction?

(3) How do instructors' perceptions of Peer Instruction relate to how they implement Peer Instruction?

\section{BACKGROUND}

In this section we discuss several ideas and related work that has shaped the design of our study and our interpretation of the results.

\section{A. Peer Instruction}

We have chosen to focus our study on the instructional strategy of Peer instruction because it is the most widely known and used RBIS for introductory quantitative physics $[7,8]$. A Web survey of a randomly selected sample of U.S. physics instructors found that $63.5 \%$ of faculty report that they are familiar with PI and $29.2 \%$ of faculty report using 
PI [7]. These were the highest levels of knowledge and use of all of the 24 RBIS asked about in the survey.

Peer Instruction was developed by Mazur for use in his large lecture introductory physics courses at Harvard University. In a PI class, the instructor delivers a short lecture (7-10 $\mathrm{min}$ ) followed by a multiple-choice conceptual question. Students first think about the question and answer it individually (often using a personal response, or "clicker," system), then discuss their answer with a nearby classmate(s), and, finally, revise their answer. Based on student responses to the multiple-choice question, the instructor may decide to move on to the next topic or to continue with the current topic. Studies by Mazur and his colleagues have shown that PI is successful in improving student learning of physics content $[2,4,5,9,10]$. Similarly positive results have been found in a variety of secondary implementations in physics classrooms at a wide variety of institution types [3,11]. The PI pedagogy has also spread to other science disciplines [12-16]. There is a lack of conclusive results regarding whether PI is effective at reducing the gender gap in student performance $[9,17,18]$.

\section{B. Process of instructional change: An overview}

Rogers [19] proposes that individuals adopt innovations (i.e., new ideas or practices) in a process that occurs over time in a series of five stages: knowledge about the innovation, persuasion about the benefits of the innovation, decision to use the innovation, implementation of the innovation, and confirmation of continued implementation of the innovation (Ref. [19], p. 162). We do not consider there to be distinct boundaries between these stages. Rather, we expect that an individual can be engaged in activities from multiple stages simultaneously and may not necessarily proceed through them sequentially in time. For example, an instructor may develop additional knowledge about an innovation through experimenting with implementing it, or an instructor may be persuaded to use an innovation through tinkering with it in the classroom and finding evidence of success. Rogers's model and others' work on instructional decision making $[20,21]$ also suggest that instructors' perceptions of the innovation and of teaching and learning are important at all phases of the innovation-decision process.

In modeling change efforts, researchers have suggested that an individual's impression of an innovation may vary depending on whether or not they have experienced using the innovation [22-24]. For example, the perceptions of an instructor with no experience using PI may be largely based on imagined hypotheticals, whereas other instructors that have tried and abandoned the innovation may have direct criticisms based on the challenges they encountered in attempting to use the innovation. We initially began our study planning to make this distinction in our analysis of instructors we interviewed; however, this turned out not to be a feasible approach largely due to many instructors' approach to tinkering with instructional strategies.

Researchers have established that when instructors take up instructional strategies they often do so in bits and pieces, adapting the strategy in the process $[7,20]$. For example, some instructors that reported on a survey to be former users of PI had never fully implemented PI as a package, but rather only had tried a few selected features [25]. This did not, however, prevent these instructors from using their personal experiences with a partial implementation to judge the effectiveness of PI. An implication of this kind of uptake is that our intuitive categories of nonuser, former user, and user relative to a packaged instructional strategy turn out to not be very useful. As discussed in Sec. III, this led us to categorize respondents in this study based on the number of PI features that they described using rather than their self-described user status (for more details see Ref. [26]).

\section{Our approach to modeling faculty perceptions within a sociocultural context}

Our thinking about instructor decision making with respect to adoption of new instructional strategies is based on a number of theoretical perspectives. Below, we summarize these perspectives and highlight how they impact our study design, data analysis, and interpretation of results.

The innovation-decision process depends not only on individual characteristics, but also on situational characteristics.-Much research and most dissemination strategies explicitly or implicitly take the perspective that faculty use of RBIS is based on individual decision making [21,27-31]. Other researchers have documented the large amount of adaptation, invention, and reinvention that occurs in the instructional change process [20,21,32]. In part, this is because the potential outcome space available for faculty is likely to be constrained by both their mental conceptions of what appropriate instruction looks like and their perceptions of situational constraints [21,33]. In this study we explicitly invited faculty to comment on a variety of situational characteristics.

Instructors' perceptions depend on the specific innovation being considered and are influenced by the means by which they learned about the innovation.-Instructors are exposed to RBIS through a variety of means, most typically through conversations with professional colleagues, journal articles and (or) books, formal presentations, or workshops [26,34,35]. Through these communication mechanisms, instructors (at times in negotiation with others) develop some understanding of what a particular RBIS is and this invariably has some dependence on the form of the particular innovation. For example, the fact that PI involves students discussing or working together may influence the ways in which faculty see PI as fitting into their instructional practices. That said, we also have strong evidence that not all features of a given instructional strategy are likely to be equally salient to all potential users and an individual's 
understanding of what constitutes the innovation may vary greatly from that of the developers or highly knowledgeable science, technology, engineering, and mathematics (STEM) education experts $[26,36]$. In this way, we see the meaning that instructors are making of a particular RBIS as emerging from a combination of influences: (1) how the RBIS was portrayed in informal communication channels where instructors negotiate understandings with their colleagues; (2) how the RBIS was cast in formal communication channels, such as books, articles, presentations, or workshops; and (3) the particular lens or schema that an instructor brings to making sense of these experiences. For this reason, we grounded our interview discussions in a specific, strategically chosen RBIS, Peer Instruction.

Instructors' perceptions depend on the specific course setting they are considering using the innovation within.Instructors have varying intuitions about what is feasible in a 30 person course setting as compared to a large enrollment course setting with more than 150 students [30]. Similarly, instructors may have different expectations about what is instructionally appropriate when teaching an elective conceptually based physics or astronomy course to nonscience majors than they do for what is appropriate for teaching a calculus-based physics course to science majors [30]. We have chosen to ground this set of interview discussions with instructors in the context of teaching introductory quantitative physics courses though other aspects of the course contexts within which instructors work may vary (such as classroom layout, class size, the prior preparation of the student population, etc.).

Instructors' perceptions depend on the specific departmental and institutional contexts within which they work.We view instructors as embedded within a sociocultural context. Instructors shape this sociocultural context and simultaneously are shaped by it [37]. Our starting assumptions are akin to those used by Lattuca and co-workers $[38,39]$ whose model of the "academic plan within sociocultural context" describes that "the success of any educational innovation and change" is "affected by the response of real people (with particular experiences, backgrounds, needs, and desires) engaged in complex and variegated sociocultural and organizational context" (Ref. [38], p. 2).

Features of departmental and institutional context include the following (Fig. 1): (1) norms for how faculty talk about and collaborate in teaching, (2) norms for how faculty respond to experimenting with innovative approaches to teaching, (3) norms for recognizing or providing resources for instructional innovation, and (4) material constraints such as technology availability, classroom space layout, etc.

These ways of conceiving of the instructional change process guided our interview protocol design as well as our analysis approach (i.e., what we took as evidence of a "perceived constraint" or a "perceived affordance"; what "counted" for us as a perceived affordance or perceived

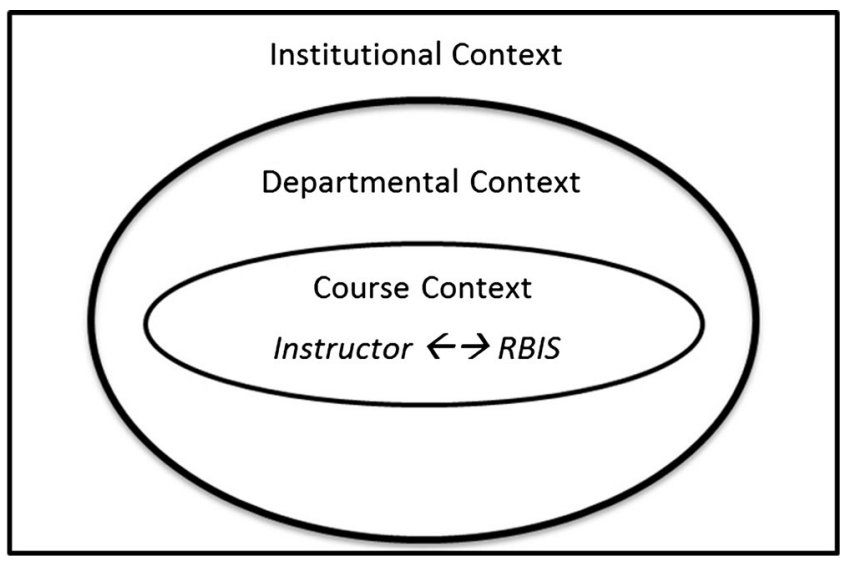

FIG. 1. Frames of context [37] that shape an instructor's perceptions of an instructional strategy.

constraint). When we report on perceived affordances and constraints that instructors see toward use or nonuse of PI or PI features, we see these as importantly emergent from this particular system (as shown in Fig. 1) not solely within the purview of the individual instructor.

\section{Perceived affordances and constraints}

Our use of the term affordance aligns with that of Gee: "Any environment in which an individual finds him or herself is filled with affordances. The term 'affordance' (coined by Gibson [40,41], see also [42]) is used to describe the perceived action possibilities posed by objects or features in the environment. The affordances of an individual's environment are what the individual can perceive as feasible to, in, on, with, or about the objects or features in that environment" (Ref. [43], p. 81). In this sense we have investigated the action possibilities that instructors perceive regarding the use or potential use of PI in relation to particular environmental conditions (or nested instructional contexts as shown in Fig. 1). As such, the affordances we report on are at times closely tied to the specific features of PI and at other times reflect an instructor's evaluation of the innovation in relation to a specific set of environmental conditions. Affordances span a broad spectrum of sources, including both internal sources, such as context-specific beliefs and expectations, as well as external sources, such as environmental structures. Likewise, we use the term constraint in opposition to affordance, i.e., any quality which restricts an individual's perceived possibilities to perform an action. In this analysis we consider the perceived affordances and constraints of faculty which may be consequential for their adoption decisions and actual or potential implementation of PI.

\section{E. Prior work investigating supports and barriers to instructional change}

Many studies in higher education have suggested barriers to educators changing their instruction such as lack of 
pedagogical training, lack of incentives or recognition for excellence in teaching, lack of resources, lack of time or overwork, and strained relationships with dogmatic or prescriptive change agents [20,44-49]. Few studies, however, have documented how salient these barriers are to faculty. In our study we work to document how salient and prevalent these barriers are to faculty in the context of deciding to use and implement PI specifically.

Michael's work documents some of the barriers to active learning that were perceived by a broad assortment of faculty [50]. At his workshop titled "Active Learning? OK, but... Breaking Down the Barriers," he solicited the perspectives of 29 faculty members of higher education from various disciplines (7 STEM and 22 humanities). The faculty in attendance worked in small groups to respond to the following prompt, "As a group, generate a list of all the barriers to teachers adopting an 'active learning' approach to their own teaching." Based on the group's in-person discussions, the author refined the educators' statements expressing perceived barriers. There is significant overlap between the barriers that Michael identifies and those that are identified in our study. Some barriers that emerged in our analysis and not in Michael's analysis may be due to differences in the selection biases in our two distinct samples (i.e., Micheal's set of instructors self-selected to attend this workshop and likely came with relatively high interest and motivation toward the use of active learning). Interesting differences in starting assumptions begin to emerge upon further comparison of our investigations. For example, Michael proceeded to group the barriers identified into three categories: student characteristics or attributes, teacher characteristics or problems that directly affect teachers, and pedagogical issues that affect student learning. Within this category scheme systemic or structural concerns have been deemphasized. This fact plays out in interesting ways when one compares our analysis with that of Michael's, which we will return to after presenting our findings.

Even fewer studies have attempted to model what factors support educators in changing their instruction. One notable exception is the well-documented importance of educators' dissatisfaction with their current instructional practices.

Deeper knowledge of the perceptions of faculty can guide efforts to better support faculty through the implementation process.

\section{RESEARCH DESIGN AND METHODOLOGY}

We report on interviews with 35 physics faculty. In addition to the analysis reported here, which focuses on the perceived barriers and affordances to Peer Instruction, we also analyzed the interviews to better understand how faculty learned about PI, what they knew about it, and how they used it. That analysis is reported in another paper along with a detailed description of data collection methodology [26]. We encourage readers interested in a greater level of detail about our methodology to consult that paper. Here we offer a more streamlined description.

\section{A. Interview participants}

Our interview sample was drawn from faculty who completed a Web-based survey as part of a previously published research study [7]. They were selected to represent a variety of institution types, faculty position, knowledge and use of research-based instructional strategies (RBIS), years of teaching experience, and gender. Interviewees were selected who expressed on the survey that they were either users or former users of Peer Instruction or that they knew about Peer Instruction but did not use it or any other RBIS. They were contacted through Email to request a telephone interview and were offered $\$ 75.00$ to participate in the one-hour interview.

\section{B. Interview procedures}

Each interview was conducted by one of us. The interviewers followed a semistructured interview protocol. The semistructured interview protocol asked faculty to describe the following:

(a) how and when they became aware of PI,

(b) how and why they began to use PI,

(c) what they see as the strengths and weaknesses of PI,

(d) what their instructional practices are in introductory quantitative physics courses,

(e) how they use PI specifically,

(f) how they implement (or modify or discontinue) specific features of PI,

(g) how they perceive aspects of their departmental context, and

(h) how they know if their instruction is working.

Potential follow-up prompts were described in the protocol to encourage faculty to elaborate; however, the interviewer improvised specific follow-up questions based on relevance to consensus research questions and the research team's emerging interests. The interviews typically lasted about an hour, were audiorecorded, and subsequently transcribed.

\section{Analysis procedures}

The analysis and coding of the interview transcripts reported in this paper was guided by the following analytical questions:

- What reasons do faculty give for initially trying PI (or aspects of PI)?

- What reasons do faculty give for not trying PI (or aspects of PI)?

- What reasons do faculty give for using, modifying, or abandoning PI (or aspects of PI)?

- What do faculty see as the strengths and weaknesses of PI? 
The interviews were analyzed using emergent coding with the assistance of qualitative analysis software (Atlas.ti). The research team first analyzed four interviews collaboratively to develop an initial coding scheme. The coding scheme was then refined, with definitions becoming more fully explicated, through analysis of additional interviews. Throughout the iterative revision process, a codebook was created to capture consensus definitions of codes. As significant changes to the coding scheme were made, coding of prior interviews was revisited. Each interview was independently coded by two researchers. Differences in coding were resolved through discussion. In these discussions, researchers considered not only the final coding designation, but also compared the evidence from the transcript that informed the coding decision. Descriptions of codes associated with specific research questions will be presented as they become relevant in the discussion of the research findings.

Although interview participants were selected based on their self-described user status, we found that these selfdescriptions did not help us understand much about their actual use of PI features [25]. Thus, we grouped instructors into categories based on how many of the 9 PI features they indicated using in their current practices during the interview: PI nonusers (uses 0/9 PI features), mixed users (uses $1 / 9$ to $6 / 9$ PI features), and high users (uses $7 / 9$ to 9/9 PI features). This process and the categories are described in more detail in a separate paper [25].

In addition, we captured some aspects of instructors' change trajectories (i.e., their current and prior experiences with PI and other innovative teaching practices). To capture this, we choose to synthesize instructors' change trajectory in semistructured paragraphs on (1) their decision-making process behind coming to use PI or parts of PI, (2) holistic description of current teaching practices, and (3) changes the interviewee had made to their teaching over time. Our analysis allows us to say a few things: all mixed users and high users use some features of PI in their current instructional practices (as characterized at the time of the interviews). The nonusers use no features of PI in their current instructional practices. Based on our analytical semistructured paragraphs, we can infer that 7 out of the 10 PI nonusers seem to have no experience using any PI features in their past instruction, while 3 of the 10 PI nonusers seem to have had some prior experiences using some features of PI (though they do not currently use any features of PI). Since there are only 3 instructors that fit this description, we were not able to characterize their impressions of PI separately from other nonusers. So when we report on the impressions of PI nonusers, we are reporting on the combined perspectives of those with no instructional experience with PI features and those who have abandoned some PI features based on some instructional experience with those features (such that they no longer use any feature of PI).
Analytical limitation.-An important limitation of any investigation of individuals' thinking processes is that individuals are not always aware of their thinking processes. In this study, some of our participants may have generated some of their ideas about perceived affordances and perceived constraints on the spot in the context of the interview. In this sense, some of these reasons that faculty give may result from trying to justify their choices and practices to us specifically (post hoc rationalization) and may not accurately reflect what informed their decision making at the time (such as other instinctive or emotional factors).

\section{FINDINGS}

\section{A. What reasons do faculty give for aligning their instruction with Peer Instruction?}

Table I presents a rank-ordered list of reasons given by more than $10 \%$ of interviewees for aligning instructional practices with PI along with a sample quotation. Summarizing definitions of each of these codes are provided in Appendix A.

Several points are important to note when considering these findings. First, it was very common for faculty to have multiple reasons to use and multiple reasons not to use Peer Instruction or one of its components. Thus, a decision to use is presumably based on weighing multiple positive and multiple negatively perceived attributes of PI in relation to their instructional setting (at least implicitly). Second, the percentages listed for the prevalence of each category represent faculty members who specifically mentioned a particular affordance in our discussion. Since these themes emerged from our conversations with faculty, we did not specifically ask faculty to comment on the applicability of each of these potential reasons. It is likely that the actual numbers of faculty holding a view are higher since many faculty may not have thought to mention an affordance even though they might agree if we had asked them about it explicitly.

In looking at the findings, we highlight several important implications.

Faculty are convinced of the general value of RBIS such as Peer Instruction. Faculty overwhelmingly indicate that they do not believe traditional instruction is the most effective form of instruction: the most common advantage stated of PI is simply that it is not traditional lecture-57\%. Additionally, large numbers of faculty indicate general beliefs aligned with RBIS (i.e., approximately half of faculty felt an advantage of PI was that it promoted active learning, 40\% said that PI just intuitively made sense, $30 \%$ liked that it got students working together, etc.). This finding is consistent with previous findings $[1,20]$ and has important implications for professional development efforts which often focus on convincing faculty of the shortcomings of the lecture method. Many instructors, it turns out, are already aware of the 
TABLE I. Affordances of Peer Instruction. Rank-ordered list of reasons given for aligning instructional practices with PI (or PI element).

\begin{tabular}{|c|c|c|}
\hline Affordance code & Percentage & Example quotation \\
\hline Dissatisfaction with lecture & 57.0 & $\begin{array}{l}\text { Something that I think (when you are up there lecturing you are vaguely always aware of, but } \\
\text { never really want to admit to yourself) is that after about } 15 \text { min or so they are not really } \\
\text { listening to you anymore. Or they are not really actively thinking anymore. }\end{array}$ \\
\hline $\begin{array}{l}\text { Evidence of effectiveness } \\
\text { from personal experience }\end{array}$ & 54.0 & $\begin{array}{l}\text { Pretty much the first few times I tried it, I saw how successful it was ...I think seeing it in } \\
\text { action was definitely the most compelling. }\end{array}$ \\
\hline Gets students active & 49.0 & $\begin{array}{l}\text { Well the strength is certainly that it engages the students. It gets them thinking about it. If they } \\
\text { are just sitting there passively trying to take in information, they are not thinking about } \\
\text { things and they are really not absorbing it either. }\end{array}$ \\
\hline $\begin{array}{l}\text { Departmental support or } \\
\text { encouragement }\end{array}$ & 46.0 & $\begin{array}{l}\text { I learned about it from my college. I've been here } 10 \text { years and when I arrived, they had settled } \\
\text { on this text and settled on this general approach. And it seemed eminently reasonable to me. } \\
\text { So I was happy to adopt it and learn from them. }\end{array}$ \\
\hline $\begin{array}{l}\text { Evidence of effectiveness } \\
\text { from data }\end{array}$ & 42.9 & $\begin{array}{l}\text { I know that the data ... shows that when they do the peer instruction with each other, that they } \\
\text { end up learning more and ...the retention is higher....I don't think that that's in much } \\
\text { dispute - and that's a good thing of course }\end{array}$ \\
\hline $\begin{array}{l}\text { Intuitively makes sense to } \\
\text { me }\end{array}$ & 37.1 & $\begin{array}{l}\text { In spite of doing well in standard Physics curriculum I never felt like I learned anything in a } \\
\text { lecture class... and even with the best faculty so I think I just always had an inherent belief } \\
\text { that that's not really how people learn physics. They really learn by doing problems or doing } \\
\text { things or seeing things. }\end{array}$ \\
\hline $\begin{array}{l}\text { Provides feedback to the } \\
\text { instructor }\end{array}$ & 34.3 & $\begin{array}{l}\text { When I lecture about something and I think oh that was so clearly presented and they're all } \\
\text { nodding so they must get it and then I can see from their response, the peer instruction } \\
\text { question, that really they don't and it brings out a lot of issues of misunderstanding that I } \\
\text { wouldn't have been aware of otherwise. }\end{array}$ \\
\hline $\begin{array}{l}\text { Gets students working } \\
\text { together }\end{array}$ & 31.4 & $\begin{array}{l}\text { I'm just following back on my own life as a student. It was very useful if you just sat down } \\
\text { together with a bunch of people. }\end{array}$ \\
\hline $\begin{array}{l}\text { Encourages depth of } \\
\text { understanding }\end{array}$ & 26.0 & $\begin{array}{l}\text { I noticed it has caused criticism from my colleagues in the past that I haven't gotten through } 15 \\
\text { chapters, and I've only got through } 12 \text {. Although I would maintain in my defense, well they } \\
\text { know those } 12 \text { chapters really well now and in two years' time if you were to retest them, } \\
\text { I'm sure my students would not be falling back into the misconceptions whereas your } \\
\text { students might well be doing that. }\end{array}$ \\
\hline $\begin{array}{l}\text { Students learn by hearing a } \\
\text { peer's explanation }\end{array}$ & 26.0 & $\begin{array}{l}\text { Our [instructor] framework for the problem tends to be just completely different than theirs } \\
\text { [the students] is and that causes a communication barrier. And so if you can have the } \\
\text { students explaining the problems to one another many times they will find an alternative } \\
\text { view of the problem that will be helpful. }\end{array}$ \\
\hline $\begin{array}{l}\text { Students learn by giving an } \\
\text { explanation to a peer }\end{array}$ & 23.0 & $\begin{array}{l}\text { And when students try to explain themselves to each other, they're making their own ideas } \\
\text { clear in their own minds. You know, the active articulating their thoughts helps them solidify } \\
\text { their understanding. }\end{array}$ \\
\hline $\begin{array}{l}\text { Forces more students to } \\
\text { participate }\end{array}$ & 20.0 & I think a strength is it encouraged students to participate who otherwise would not. \\
\hline Breaks up lecture & 17.0 & $\begin{array}{l}\text { If I just stand there for } 50 \text { min talking they get-I can tell that people are tuning out. So if } \\
\text { nothing else, it provides a break and forces students to focus. }\end{array}$ \\
\hline Has a conceptual emphasis & 17.0 & $\begin{array}{l}\text { The strength of Mazur's Peer Instruction is that it does value concepts as well as mathematical } \\
\text { equations. }\end{array}$ \\
\hline $\begin{array}{l}\text { Easy transition from } \\
\text { traditional lecture }\end{array}$ & 17.0 & $\begin{array}{l}\text { So I think I started with stuff that was like okay, I can pull three questions out of Mazur's book } \\
\text { or out of Knight's workbook and put it in class tomorrow. I don't have to have equipment or } \\
\text { websites set up and contact IT and dah-dah-dah-dah-dah. }\end{array}$ \\
\hline Students like it & 17.0 & $\begin{array}{l}\text { I had some experience with it [Peer Instruction] from where I had an adjunct... The students } \\
\text { seem to like it. And it kept them interested. }\end{array}$ \\
\hline $\begin{array}{l}\text { Evidence of effectiveness } \\
\text { based on the opinion from } \\
\text { a valued other }\end{array}$ & 11.0 & $\begin{array}{l}\text { Having a friend and colleague that is a very strong advocate for it and is a good physicist and } \\
\text { very good at making arguments ... it's hard to just say well I'm not going to use it. I was } \\
\text { compelled by him and others to consider the idea. }\end{array}$ \\
\hline $\begin{array}{l}\text { Improves the atmosphere in } \\
\text { the class }\end{array}$ & 11.0 & $\begin{array}{l}\text { It engages them with each other and creates a much greater sense of community in the } \\
\text { class.... with the students getting to know each other and them feeling that the classroom is } \\
\text { much less hostile ...I have really noticed how it changes the atmosphere in a classroom. }\end{array}$ \\
\hline $\begin{array}{l}\text { Provides feedback to } \\
\text { students }\end{array}$ & 11.0 & $\begin{array}{l}\text { The students get immediate feedback on how they did. And to me that is quite important. If } \\
\text { you wait for a week or two to get the quiz back, the students already forgotten... So } \\
\text { immediate feedback, I think, is a component. }\end{array}$ \\
\hline
\end{tabular}


shortcomings of the lecture method and believe that student-centered practices have the potential to be more beneficial. To a large extent, they have already "bought-in" and do not need a lot of convincing.

Peer Instruction may serve as a "gateway" reform. As mentioned previously, we specifically targeted PI in our interviews because our previous research showed us that PI is currently the most commonly used of all the RBIS in physics. Unsurprisingly, nearly $20 \%$ of faculty specifically mentioned, without being directly asked, that an advantage of PI was that it was easy to incorporate into traditional lecture. As noted above, faculty are generally dissatisfied with lecture and want to use more active engagement methods. For the instructor new to these methods, PI may represent a plausible avenue toward incremental change (i.e., lower effort and lower risk than wholesale change required by more radical RBIS). It is important to note that the second most commonly mentioned affordance was "evidence from personal experience." In other words, once faculty actually try PI in some form, many faculty are often further convinced by what they see happening in their classroom and with their own students. For a few faculty merely witnessing another instructor's effective use of PI at their institution was compelling as evidence of success. For some of these instructors who find incremental change attractive and then see PI work in situ in classrooms, PI use or PI's observed use might plausibly encourage faculty to consider more extensive reforms later on. However, while a majority of faculty report personal experiences with PI that further convince them of its value, large numbers of faculty also report some sort of difficulty in implementing PI which could potentially cause them to abandon PI all together. We will come back to this critical point for further discussion in the next section.

Encouragement from local community at the departmental level matters. Encouragement from local departmental community members took many different forms in our interview data. Some faculty expressed that being innovative in the classroom was generally valued by their departmental colleagues. At times, departments had even established some norms regarding the use of PI (or other innovative teaching methods) which new instructors were inculcated into using. At other times, there were individual innovators in the department that other colleagues reported talking to about teaching and getting instructional materials from. In this example, an instructor might say that an affordance of using PI is that they have a local peer faculty to get advice and materials from. The prevalence of this affordance shows that the early adoption of RBIS, such as PI, might be seeding and cultivating innovative classroom practices more broadly at some institutions.

\section{B. What reasons do faculty give for not aligning their instruction with Peer Instruction?}

Table II presents a rank-ordered list of the reasons given by more than $10 \%$ of interviewees for not aligning instructional practices with PI along with a sample quotation. Summarizing definitions of each of the perceptions codes are provided in Appendix B.

In looking at the findings we highlight several important implications. These are described in the following.

Instructors report that finding the required time and energy to change is a significant barrier. This concern arose in many different flavors. At times interviewees were quite vague about what specifically constrained their time and energy, only describing a broad sense of feeling overwhelmed with the responsibilities and demands on their time. The majority of comments captured by the "requires time and energy to change" category include sentiments such as (a) time to prepare for class (figure out what to do in class on a day-to-day basis), (b) time to understand PI as a strategy in more detail, (c) time to figure out technology, (d) time to talk, reflect, and discuss teaching, and (e) time to foster an intellectual community around teaching. Faculty comments about "feeling overloaded with job duties" would have been coded under both "requires time and energy to change" and "structural, overloaded with duties." "Structural, overloaded with duties" was relatively rare, $14 \%$, and was only used to capture faculty comments about specific aspects of their job description or institutional situation that led to them being stretched too thin (such as being short-staffed or having in intensive teaching load). We will return to this theme of "time and energy required to change" in the discussion as it is significantly enlightened by further analysis presented in the next section.

Faculty feel a lot of tension between using PI and "covering content." Half of all faculty indicated they felt PI use would make it more difficult for them to cover the full range of course material they personally felt should be part of the course. Another quarter of faculty indicated a tension between using PI and covering content they felt needed to be covered due to some external expectations. It is common for change agents to state that "less is more" pointing out that "covering" content does not ensure that content is learned and that regardless of what is covered students learn more when actively engaged. While faculty do find this argument to be of some help (we found that many faculty expressed the same belief that students can learn more in a course that covers less material), in most cases this argument alone does not do enough to resolve the conflict for them.

It is likely that an individual's concern about content coverage stems from a very complicated set of circumstances. As noted above, faculty often feel pressure from others to cover a set curriculum (i.e., the department has adopted a set coverage list, or courses students take later assume familiarity with a particular set of content). In this situation, an individual may not feel they have the ability to cover less even if they believe it would benefit their students to do so. Even when there are no formal 
TABLE II. Constraints of Peer Instruction. Rank-ordered list of reasons given for NOT aligning instructional practices with PI (or PI element).

\begin{tabular}{|c|c|c|}
\hline Constraint code & Percentage & Example quotation \\
\hline $\begin{array}{l}\text { Requires time and energy to } \\
\text { change }\end{array}$ & 57 & $\begin{array}{l}\text { The biggest problem, aside from this whole student popularity contest issue, is time, ... } \\
\text { having enough time to sit down and figure out what I'm going to do in class. So } \\
\text { sometimes in the past... you might get a developmental block, like an extra block off } \\
\text { to develop the class or something like that. That would be really useful. }\end{array}$ \\
\hline $\begin{array}{l}\text { Content coverage concerns } \\
\text { based on personal } \\
\text { commitment }\end{array}$ & 49 & $\begin{array}{l}\text { There is a certain amount of material and a certain order to that material that we're going } \\
\text { to get through in the course of the semester. What it does change is the rate at which } \\
\text { we move onto the next topic. And, of course, for me to say those two things there's an } \\
\text { inherent contradiction. If they're having trouble day after day after day then in } \\
\text { principle you would slow way down, but then you wouldn't get through the requisite } \\
\text { amount of material }\end{array}$ \\
\hline $\begin{array}{l}\text { Difficulty getting students } \\
\text { engaged }\end{array}$ & 49 & $\begin{array}{l}\text { Getting students to interact in a meaningful way I think sometimes is an issue. We } \\
\text { have-just our student population is real varied. So we could have students with a } \\
\text { lot of different ability levels, and so just getting them to interact with each other. }\end{array}$ \\
\hline $\begin{array}{l}\text { Student shortcomings make } \\
\text { them unable to learn } \\
\text { through PI }\end{array}$ & 37 & $\begin{array}{l}\text { It seemed like a good idea and it's, he [Mazur] said that he thought that peers could } \\
\text { explain things to peers better than physicists could explain it to undergraduates in } \\
\text { many cases. And that sounded good but I think physics is really hard to explain in a } \\
\text { way that makes sense after you leave the discussion, in a way that you retain the } \\
\text { explanation and it makes sense in a bigger context. And I think he's done a lot more } \\
\text { on this than I have, but I just think he's underestimating how difficult it is to really } \\
\text { explain this, that's one of the reasons physics is taught so badly, it's not easy to } \\
\text { explain things }\end{array}$ \\
\hline $\begin{array}{l}\text { In personal experience it did } \\
\text { NOT work }\end{array}$ & 34 & $\begin{array}{l}\text { I'm not sure what the biggest difficulty was other than I felt like it really stopped the } \\
\text { class on occasion... especially if it was a conceptual question that } 90 \text { percent of the } \\
\text { people got immediately, it just felt like a waste of time. }\end{array}$ \\
\hline Structural, lack of resources & 34 & $\begin{array}{l}\text { I would say to make it [the continued use of } P I] \text { better, it would be helpful to, you know, } \\
\text { have more access to physics teaching literature and more access to teaching } \\
\text { conferences }\end{array}$ \\
\hline Structural, class size & 31 & $\begin{array}{l}\text { I generally do Peer Instruction when I have class size between } 50 \text { and } 100 \text { people. If I } \\
\text { have more than } 100 \text { people it gets too much out of hand. I tried it with a } 200 \text { people } \\
\text { class and it wasn't successful because the groups are just too-you can't, as a single } \\
\text { instructor cannot-I don't know, you don't have enough control over what's going on } \\
\text { in the room during that time if you have too many people. }\end{array}$ \\
\hline $\begin{array}{l}\text { Structural, lack of } \\
\text { appropriate classroom }\end{array}$ & 31 & $\begin{array}{l}\text { Well we have probably one room that I teach and that I think is well suited for it }[P I] \text {, } \\
\text { where they actually are at round tables, but they can still all see the front of the } \\
\text { classroom essentially. So they can face each other. And in a traditional chairs facing } \\
\text { forward, all in a row format, the Peer Instruction thing is a little more difficult because } \\
\text { they can really only talk effectively with probably the person next to them. With one } \\
\text { other person it is hard for them to have a little bit more than two people discussing.... } \\
\text { I'd say the majority [of classrooms] are not well suited [for use of Peer Instruction] }\end{array}$ \\
\hline $\begin{array}{l}\text { Trouble finding good } \\
\text { questions }\end{array}$ & 31 & $\begin{array}{l}\text { [I have a] little bit more of a global understanding of what some of those materials were } \\
\text { that I got. But at the same time I have to say, it's like there's so much that it's just } \\
\text { daunting. Like I have no idea really where to start if that makes sense. ...there's just } \\
\text { so much research and so many materials that I just-I feel like, well, it's so hard to } \\
\text { figure out where to start that I don't even know if I want to start. }\end{array}$ \\
\hline $\begin{array}{l}\text { Difficulty getting student } \\
\text { buy-in }\end{array}$ & 29 & $\begin{array}{l}\text { I would say occasionally there is student resistance to it. You know, some classes I'll } \\
\text { have maybe one person who simply insists that they're not there to do that, so that can } \\
\text { be problematic }\end{array}$ \\
\hline $\begin{array}{l}\text { Current practices are } \\
\text { effective }\end{array}$ & 26 & $\begin{array}{l}\text { I still, I know there's a lot of talk about lectures being not great, but I feel like I still- } \\
\text { you know most of my knowledge came from there and, of course... So if it's done } \\
\text { well, the right, I still feel like there is a lot of value in there. So I do not completely say } \\
\text { that lectures are the way of the past }\end{array}$ \\
\hline $\begin{array}{l}\text { Intuitively don't think that } \\
\text { PI will work }\end{array}$ & 26 & $\begin{array}{l}\text { But I have a great fear that my class would collapse completely and there would be a } \\
\text { revolution if I really operated on the expectation that they were ready to go when they } \\
\text { walk in the door. }\end{array}$ \\
\hline
\end{tabular}


TABLE II. (Continued)

\begin{tabular}{|c|c|c|}
\hline Constraint code & Percentage & Example quotation \\
\hline $\begin{array}{l}\text { Content coverage concerns } \\
\text { based on external } \\
\text { requirements }\end{array}$ & 23 & $\begin{array}{l}\text { It }[P I] \text { takes a lot of time. And when I have incorporated a lot more of it and then have } \\
\text { covered fewer topics, you know, I get a lot of unhappiness from the students, } \\
\text { particularly the pre-med students who are like, you know, you didn't cover fluids and } \\
\text { that's on the MCAT. ... so time is the biggest downside. }\end{array}$ \\
\hline $\begin{array}{l}\text { Content coverage concerns } \\
\text { based on institutional } \\
\text { expectations }\end{array}$ & 20 & $\begin{array}{l}\text { It [departmental arguments against } P I \text { ] was mainly focused on the lack of coverage } \\
\text { because I don't think they could come up with any real criticisms of the Peer } \\
\text { Instruction method. It was the content and the fact that I didn't get through as much } \\
\text { material. There were also issues to do with emphasis as well that the department chair } \\
\text { felt I should spend a lot of time on the vector cross product because he needs to use } \\
\text { that in his next class. }\end{array}$ \\
\hline $\begin{array}{l}\text { Structural, assessment } \\
\text { barriers }\end{array}$ & 17 & $\begin{array}{l}\text { They, when you come up for tenure, send a letter out to every student that you've ever } \\
\text { had in a class saying, what do you think of this person? So it could be, you know, four } \\
\text { years later after they've had you. They send this letter out and then the students- } \\
\text { whoever feels like writing back writes back. So who writes back, of course, are the } \\
\text { ones that really liked you and the ones that really hated you. And so if you have more } \\
\text { than, you know, say two that really hated you that wrote back, you won't get tenure. } \\
\text { So that is a very large impediment, I would say to really being able to experiment with } \\
\text { classes. Because when you experiment with classes sometimes it doesn't work }\end{array}$ \\
\hline $\begin{array}{l}\text { Structural, course schedule } \\
\text { structure }\end{array}$ & 17 & $\begin{array}{l}\text { If we always have to have a certain } 9 \text { a.m. lecture, we cannot do some combined lecture } \\
\text { recitation for } 2 \mathrm{~h} \text { or, you know, that kind of thing. And some formats I think that } \\
\text { would work better to have a longer-to have longer time periods to work. }\end{array}$ \\
\hline Data NOT convincing & 14 & $\begin{array}{l}\text { It's like any educational technique, the reviews are mixed. The reviews from students } \\
\text { are mixed. But I think all of these techniques are definitely worth looking into. I } \\
\text { should mention one problem I have with what I see as the entire physics education } \\
\text { research conundrum, I guess. Is that in order to do good educational research, you } \\
\text { need large body counts. And so, it makes sense that researchers in that area go for } \\
\text { places with large body counts. But what that does is it selects a student body that } \\
\text { doesn't always apply to small liberal arts colleges }\end{array}$ \\
\hline $\begin{array}{l}\text { Mismatch between PI and } \\
\text { course goals }\end{array}$ & 14 & $\begin{array}{l}\text { I think that was part of my initial apprehension thinking gee, if I spent more time on } \\
\text { these kinds of qualitative questions, I would have to do fewer numeric examples in } \\
\text { class. And that's not good because they need more examples in order to be able to do } \\
\text { the numerical homework. }\end{array}$ \\
\hline $\begin{array}{l}\text { Structural, need to } \\
\text { coordinate with other } \\
\text { instructors }\end{array}$ & 14 & $\begin{array}{l}\text { If you're going to switch to something like this you're going to have to give people a lot } \\
\text { more guidance on that. And I don't know, you know, if we would find, we would have } \\
\text { to get every faculty member who's teaching each one of our freshman sections, you } \\
\text { know, to change to a new system }\end{array}$ \\
\hline $\begin{array}{l}\text { Structural, overloaded with } \\
\text { duties }\end{array}$ & 14 & $\begin{array}{l}\text { I lose the energy and the initiative and the creativity. And, you know, I dream of - you } \\
\text { know, if I only had to teach one course I could probably teach it well. But I can't do } \\
\text { that. I have a whole bunch of courses to teach. So that's the main thing. }\end{array}$ \\
\hline Mismatch with personality & 11 & $\begin{array}{l}\text { I think I am a good lecturer. And I'm disappointed that that's not the way students best } \\
\text { learn. I am much better at preparing things ahead of time and reciting them. I am } \\
\text { better at that than I am at engaging in the moment and having to really think through } \\
\text { students' misunderstandings and misconceptions. I don't operate well in real time in } \\
\text { that way. And it can make me feel really stupid. }\end{array}$ \\
\hline
\end{tabular}

expectations placed on an instructor there are lots of subtle indications of what is expected: textbooks are typically very high on content, instructors typically experienced a course with high content coverage themselves as students, their colleagues are covering a lot of material, etc. In addition, some faculty experience an emotional attachment to particular content, i.e., "I enjoyed topic X as a student so how could I not expose my students to it" or "I've spent so much time developing all these lecture notes I hate to just drop them."
Faculty encounter implementation difficulties. Note that many of the hindrances faculty mentioned have to do with having tried PI and experiencing difficulties. For example, half of all faculty said they had trouble getting students to engage in the activities and a third said that they struggled to get students to buy into their use of PI. A third said they had tried PI and had found it not to work effectively. Another third said they ran into difficulty finding good questions to use. These findings indicated that faculty who try to use PI often encounter significant 
difficulties. These difficulties are serious enough that they can lead an instructor to abandon PI use, and could leave them less open to use of RBIS in the future.

Instructors may have implementation difficulties for a variety of reasons. As we reported elsewhere $[7,20,26,36,51]$, we have consistently found that instructors very commonly do not use RBIS as recommended by the developer. Sometimes these modifications appear to be positive, for example, to align the RBIS with the local teaching context. However, often these modifications are the result of either a lack of knowledge of what the best practice would be or a lack of understanding of the importance of some component of the strategy (i.e., many PI user's report not having students commit to an individual answer first because this takes more class time and they are concerned about covering content). Change agents need to do a better job of communicating with faculty about how to use different RBIS as well as the reasons behind (and the importance of) different aspects of a RBIS so that faculty are better positioned to modify successfully.

Faculty also have implementation difficulties because using a new strategy is difficult. Change agents often present a rosy picture of RBIS use, as if all a faculty member needs to do is follow the brief instructions and shortly they will see high learning gains from their students. The reality of change is very different. Successful teaching is a nuanced activity and change agents generally fail to give faculty adequate guidance. For example, for the instructor who is making every attempt to follow Mazur's method as outlined in the PI book but who finds the majority of their students socializing instead of discussing the concept question, what can they do? Very little guidance exists to help this faculty identify the cause of the difficulty or to be able to change the situation. This leaves them likely to abandon PI and resort back to traditional lecture.

Instructors perceive significant structural barriers. Behavior is the result of the interplay between an individual's characteristics (e.g., beliefs, knowledge, attitudes, experience, etc.) and the environment in which that individual is located [33]. An example of this is seen above where an instructor may believe students would learn more if they covered less content, and desire to do so. But, due to external requirements, the instructor still covers more content in lieu of deeper understanding. Note the large number of structural barriers mentioned by the interviewees, in addition to the content coverage expectations already discussed: lack of resources $34 \%$, class size $31 \%$, lack of appropriate room $31 \%$, assessment barriers $17 \%$, course schedule structure $17 \%$, need to coordinate with other instructions $14 \%$, overloaded with duties $14 \%$. What these faculty are essentially saying is that they are interested in using PI, or using it more, but their environment does not support it (e.g., they teach in a large lecture room where the chairs are bolted to the floor and they cannot easily access all students to engage them directly, or they are team teaching the course with another faculty who is not interested in using PI).

While it might be possible for faculty to overcome some of these situational barriers, they are in a situation where they are proverbially swimming upstream. Having to fight against their environment to enact beliefs about how to teach best makes it less likely they will use a strategy and also very likely that if they do implement they will run into significant implementation difficulties as discussed above.

\section{How do faculty perceptions of PI relate to how they implement PI?}

Motivated by prior research that suggests that the concerns of educators may vary based on their experiences using the innovation [22-24], we investigated whether faculty perceptions of PI varied based on their use of the innovation. In order to investigate this further, we specifically asked interviewees questions about their use of 9 features of Peer Instruction. These features (Table III) were developed based on published documents about PI as well as feedback from PI developer Mazur.

For each interview, we coded evidence that argued in support of or against faculty's use of each feature listed in Table III. The coded information about that feature was then assessed holistically and an assessment was made by the researcher according to whether the instructor used, partly used, or did not use each feature. At least two researchers compared their independent assessments of each interview and reached consensus based on discussion.

Based on this analysis we coded each interviewee as either a "high user," a "mixed user," or a "nonuser." Table IV provides details on these categories.

TABLE III. Nine features of Peer Instruction developed in consultation with Mazur.

\begin{tabular}{l}
\hline Adapts: Instructor adapts to student responses to in-class tasks \\
Answers not graded: Students are not graded on in-class tasks \\
Commit to answer: Individual students have a dedicated time to think about in-class tasks and commit to answers independently \\
Conceptual tasks: Uses conceptual in-class tasks \\
Tasks draw on student ideas: In-class tasks draw on common student prior ideas or common student difficulties \\
Multiple choice questions: In-class tasks have discrete answer options \\
Questions interspersed: In-class tasks are interspersed throughout class period \\
Students discuss: Students discuss their ideas about in-class tasks with their peers \\
Vote after discussion: Students commit to an answer after peer discussion \\
\hline \hline
\end{tabular}


TABLE IV. Research-assigned PI implementation groups.

\begin{tabular}{|c|c|c|c|}
\hline $\begin{array}{l}\text { Researcher-assigned } \\
\text { implementation } \\
\text { group }\end{array}$ & Definition & $\begin{array}{l}\text { Number } \\
\text { of } \\
\text { faculty }\end{array}$ & $\begin{array}{l}\% \text { of faculty } \\
\text { interviewed }\end{array}$ \\
\hline High users & Uses 7-9 PI features & 7 & 20 \\
\hline Mixed users & Uses 1-6 PI features & 18 & 51 \\
\hline Nonusers & Uses 0 PI features & 10 & 29 \\
\hline
\end{tabular}

Next we consider the perceived affordances of and constraints to PI use divided by implementation group. Figure 2 displays the average number of affordances and constraints expressed by each person in each group.

On average, each interviewee expressed approximately 12 affordances or constraints. High users cite more affordances to PI use than constraints to PI use, mixed users cite about an equal number of affordances to PI use and constraints to PI use, and nonusers cite more constraints to PI use than affordances to PI use. It is not particularly surprising to find that users have more positive perceptions of PI than nonusers. So, what about the specific affordances and constraints that each group references? What can we understand about the nature of the concerns held by each user group?

Table V lists the most prevalent perceived affordances and constraints by each implementation group, demonstrating dramatic differences. For the side-by-side comparison of the prevalence of these categories by user group, see Appendix C.

This analysis shows distinct and insightful differences between the different implementation groups. Below we discuss in more detail the key findings and implications.

High users' most common concerns relate to implementing PI in interaction with students. Mixed users' concerns reflect tensions experienced in navigating the use of PI (or PI features). Nonusers' most common concerns span structural constraints, blaming student shortcomings, and acknowledging particular conflicting personal commitments. The most common concerns of high users are getting students to engage and finding

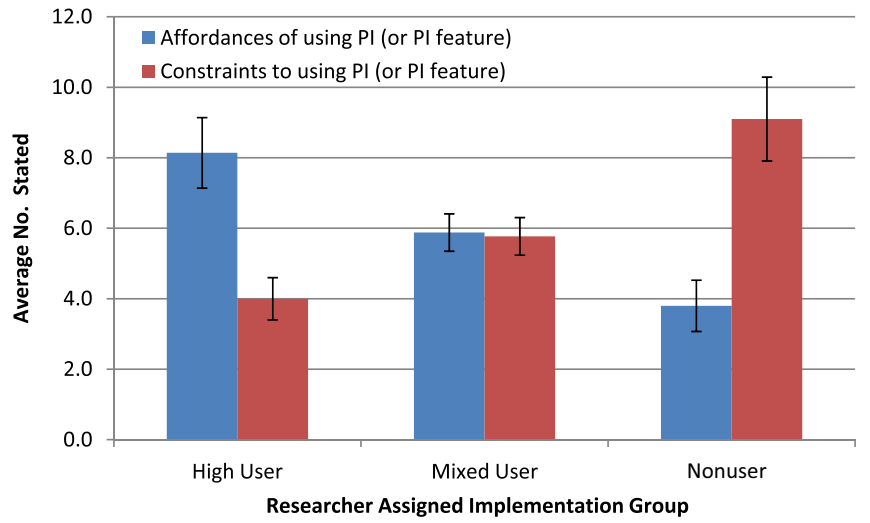

FIG. 2. Number of affordances and constraints expressed by interviewees in each researcher-assigned user group. good questions. When instructors discuss their difficulties in getting students engaged within PI tasks, they often portray this as a nuanced negotiation between them and their students (not merely blaming students for this implementation difficulty). Similarly, when they describe their challenges in finding "good" questions, they describe a struggle with both determining what makes a good question and a struggle in finding questions which met their students were they were (in term of being not too easy or too difficult, offering a challenge, but being doable). These highly salient concerns of high users have to do with the nuances of implementing PI in interaction with students. Mixed users were using multiple PI features and experiencing tensions in their use of PI. Mixed users doubted content coverage sacrifices that the use of PI demanded (in their experiences). They also felt that making instructional changes came at a heavy expense of their time and energy. This sort of tension leading to mixed use has also been documented in other studies [52]. In contrast, the concerns of nonusers centered on perceptions of structural barriers, their students' shortcomings, and particular conflicting personal commitments (e.g., to their current instructional practices and to their coverage of content). While mixed users and nonusers have some concerns in common, the nonusers have many more concerns (many of which locate instructional problems as outside their sphere of influence).

More longitudinal studies of instructors' change trajectories are needed. We note that there is no overlap in the most prevalent concerns of high users and nonusers. However, we know that at some point prior to adoption all of our high users were themselves nonusers. Given this fact, it is very interesting that the concerns that nonusers give do not overlap with the difficulties expressed by those who are fully implementing PI. Our analyses cannot distinguish between multiple plausible models regarding the observed differences between high users, mixed users, and nonusers: (1) whether there is a gap between the hypothetical barriers faculty think they will face and the barriers encountered while trying the innovation, (2) whether certain barriers become less salient as faculty become more experienced and (or) skilled at the use of RBIS, or (3) whether variation among individual faculty's mental ecologies or dispositions are responsible for these varying perceptions (maybe some of the nonusers will never look like the high users because of varying personal commitments). It is likely that many of these factors are contributing simultaneously. Following faculty over time through attempts at changing their instruction would shed light on how faculty's perceptions of constraints (and affordances) may (or may not) shift. ${ }^{1}$ Such studies could help to disentangle cases of faculty

\footnotetext{
${ }^{1}$ It would be important in these investigations to model what kinds of supports exist for faculty to modify their instruction since different kinds of shifts may be possible with different kinds of supports.
} 
TABLE V. Most prevalent reasons given for aligning or not aligning instructional practices with PI by researcher-assigned user group. Reasons are shown in this table only if the reason was cited by $50 \%$ or more of participants within the user group.

\begin{tabular}{|c|c|c|}
\hline & Most prevalent perceived affordance(s) of PI use & Most prevalent perceived constraint(s) to PI use \\
\hline High & $\begin{array}{l}\text { (1) Dissatisfaction with traditional lecture }(86 \%, 6 / 7) \\
\text { (2) Evidence of effectiveness, personal experience }(71 \%, 5 / 7) \\
\text { (3) Forces more students to participate }(71 \%, 5 / 7) \\
\text { (4) Evidence of effectiveness, data }(57 \%, 4 / 7) \\
\text { PI makes intuitive sense }(57 \%, 4 / 7) \\
\text { Provides feedback to the instructor }(57 \%, 4 / 7)\end{array}$ & $\begin{array}{l}\text { (1) Difficulty getting students engaged }(100 \%, 7 / 7) \\
\text { (2) Trouble finding good questions }(57 \%, 4 / 7)\end{array}$ \\
\hline Mixed & $\begin{array}{l}\text { (1) Dissatisfaction with traditional lecture }(78 \%, 14 / 18) \\
\text { (2) Gets students active in class }(67 \%, 12 / 18) \\
\text { (3) Evidence of effectiveness, personal experience } \\
(56 \%, 10 / 18) \\
\text { (4) Departmental support or encouragement }(50 \%, 9 / 18)\end{array}$ & $\begin{array}{l}\text { (1) Time and energy required to change }(56 \%, 10 / 18) \\
\text { (2) Personal commitment to content coverage }(50 \%, 9 / 18)\end{array}$ \\
\hline Non & (1) Evidence of effectiveness, personal experience $(50 \%, 5 / 10)$ & $\begin{array}{l}\text { (1) Time and energy required to change }(90 \%, 9 / 10) \\
\text { (2) Student shortcomings make them unable to learn through } \\
\text { PI }(60 \%, 6 / 10) \\
\text { (3) Personal commitment to content coverage }(50 \%, 5 / 10) \\
\text { Structural, lack of resources }(50 \%, 5 / 10) \\
\text { Structural, class size }(50 \%, 5 / 10) \\
\text { Current practice effective }(50 \%, 5 / 10) \\
\text { External requirement of content coverage }(50 \%, 5 / 10)\end{array}$ \\
\hline
\end{tabular}

growth and change over time (such as a nonuser becoming a mixed or high user) from instances of faculty's personal and situational factors keeping them firmly in the nonuser group.

All three user groups commonly stated evidence of effectiveness from personal experience to be a reason for aligning instructional practices with PI. Given the general lack of overlap of reasons not to align practice over user groups, we find it interesting that all groups report personal experiences that encourage their alignment with PI. It is encouraging that across faculty there is a sense from their own experiences that PI could be effective for students' learning. This theme of personal experience with new ideas via personal interactions, observability, and trialability [19] being more important than presentation of data is echoed throughout the literature on diffusion of innovations [19,53,54].

Different user groups need different kinds of support. These qualitative differences in the reasons to align or not align given by faculty from different implementation groups suggest that faculty are making meaning of this educational innovation differently. Professional development (PD) efforts should meet faculty where they are, and this will likely required more effective differentiated instruction to address the targeted concerns of different user groups within PD settings. Those who are early on in the reform process need more effort targeted toward generally convincing them of the value of an innovation, addressing concerns, and navigating structural difficulties. Once faculty begin implementing a reform they need help navigating the difficulties that arise with the subtleties of how to best implement and in learning to make appropriate modifications on their own. There are many ways that professional development leaders could pursue addressing the diverse needs of faculty. For example, experienced faculty (i.e., high users) may be a powerful resource in convincing nonusers of the value of PI (or other RBIS) and coaching their peers on how to address personal concerns and navigate structural constraints. There may be significant benefit to soliciting faculty from higher-level implementation groups to share their experiences with faculty just beginning to use PI. Faculty may be more open to hearing someone they associate with or consider as "like them" (i.e., not an education researcher) reassure and support them through their concerns. Carefully structured and facilitated faculty group work could leverage the different perspectives faculty bring to PD settings. Another strategy might be to break faculty up into groups based on their experiences implementing RBIS and design different activities for faculty with different experiences.

\section{IMPLICATIONS AND CONCLUSION}

PI is similar to and shares many significant characteristics with other RBIS. Therefore, it is reasonable to expect that findings from an analysis of the use of PI can significantly inform broad-scale model building and recommendations for impactful educational transformation. The analysis presented in this paper illuminates a number of findings useful to change agents. We summarize them below in the form of recommendations.

There are good reasons to think that many of these perceived affordance and constraints regarding PI may generalize to other RBIS. There are many affordances (such as "dissatisfaction with lecture" or "gets student active") 
that could be expected to arise in the context of many or most RBIS. Similarly, there are many constraints (such as concerns about content coverage or structural constraints) that could be expected to arise in the context of many or most RBIS. We have also used this set of coding categories to make sense of a parallel set of interviews with faculty regarding the use of Workshop Physics; many of these categories translated well. The prevalence of these categories may shift when considering other RBIS (e.g., the structural constraints of the classroom might be more consequential for the adoption of Workshop Physics) and there may be a need for additional coding categories (e.g., valuing the process of scientific inquiry or discovery). Thus, the following recommendations, although grounded in our study of PI, are written in more general terms that can apply to a broad set of change agents in higher education.

Recommendation I: Do not waste a lot of time criticizing lecture-based instruction and convincing faculty of the value of research-based strategies (Many are already dissatisfied with lecture). Past dissemination efforts have frequently focused on convincing faculty (usually with data) that lecture is ineffective and active learning will lead to better outcomes. We found no support for the idea that significant numbers of today's faculty shun RBIS because they believe in or are highly committed to lecture. A majority of faculty report being dissatisfied with lecture as a method of teaching, and dissatisfaction with lecture was the most commonly reported reason to use PI. Our data indicate that faculty generally experience lecture as disconnected from students and not ideal for their learning. Furthermore, the majority of instructors who have tried some form of active learning (i.e., using some subset of PI features) report positive feelings about its potential. This finding indicates that change agents do not need to exert much time and effort convincing faculty that active learning techniques are superior to lecture; many faculty are already aware of and believe thing.

Recommendation II: Understand and address concerns faculty have about implementing active learning techniques. When instructors appear resistant to abandoning lecture, the likely cause is concerns about implementing the new strategy within their instructional setting. Change agents should learn more about the underlying concerns of faculty and address these concerns. Change agents could perhaps have a bigger impact by doing a better job of acknowledging structural barriers (which are often downplayed if they are mentioned at all) and by helping faculty find ways to overcome them. Additionally, because many of the barriers exist due to the current (and past) culture in the physics community regarding teaching, it will be important to find ways to change the larger cultural landscape regarding how physics should be taught. As a second example, many faculty resist Peer Instruction due to feeling pressured to cover content. In order for the way to be paved for full reform toward RBIS, it is clear that a cultural shift needs to take place around the issue of how much content is "covered" (both for individual faculty and for the institutional setting within which they are embedded). This is an issue that has been known to change agents and which they have tried to address (i.e., the less is more mantra). However, our findings suggest that it is still a major impediment and that more (and more effective) efforts are needed to encourage this cultural shift in thinking. Helping faculty to resolve this conflict is likely to be a productive avenue for encouraging more RBIS use.

Recommendation III: Focus on supporting and encouraging faculty experiences with RBIS. Faculty are more convinced by their own experiences than by data. As noted above, positive personal experiences were one of the most mentioned reasons to adopt Peer Instruction and negative personal experiences with PI were frequently cited as reasons to abandon PI. This indicates the importance of getting faculty to try an innovation and to support the trial period well so that instructors are not overwhelmingly frustrated by implementation difficulties. Faculty need help understanding how to best implement an innovation and how to deal with common difficulties. If they have this support it appears likely they will see for themselves the value of the innovation and be more likely to continue using it. For the goal of sustained and effective reform, it is critical that the education research community give more focus to research on secondary implementations. We need to understand more about the implementation difficulties typical faculty encounter and in finding ways to support faculty through these difficulties. It seems likely that without providing more support for common secondary implementation difficulties there will always be a significant proportion of faculty who will try and abandon RBIS use.

Recommendation IV: Address concerns faculty new to RBIS have about the time and energy needed to change. The reasons faculty give for not trying Peer Instruction are different than the barriers reported by faculty who have actually implemented PI. Specifically, instructors appear concerned about the time and energy it will take to adopt PI. Addressing this with faculty and finding ways to support them in the initial trial period is likely important. It appears that once faculty start down the path of change their concerns about time lessen.

Our study illuminates perceived affordances and barriers of faculty toward the use of Peer Instruction and likely many other RBIS. While much of our list of affordances and barriers is not surprising, a number of reported perceptions were more common than often assumed (for example, the importance of personal experience) or less common (such as the value of data). By aligning change efforts to the perceptions of faculty, change agents can increase the impact of their efforts.

\section{ACKNOWLEDGMENTS}

This material is based upon work supported, in part, by the National Science Foundation under Grant No. DUE0715698. We appreciate feedback from Alice Olmstead and Jessica Watkins on earlier versions of this work. 


\section{APPENDIX A}

Table VI below summarizes our code definitions of reasons faculty give for aligning their instruction with Peer Instruction (or elements of PI).

TABLE VI. Definitions of perceived affordances of PI use codes (alphabetically).

Perceived affordances of PI codes and associated definitions

Breaks up lecture: PI is good for breaking up the lecture, keeping students awake or alert in class, getting students to pay attention, or addressing students' short attention span. These comments have more to do with pausing during the delivery of information (rather than getting students to do something).

Conceptual emphasis: PI is good for emphasizing conceptual knowledge for students. This code captures the interviewee's perception that focusing on concepts in introductory physics is a good thing (or aligns with the instructor's goals for this course) and that PI helps to achieve this conceptual focus.

Departmental support or encouragement: Interviewee reports either being expected to use PI since it was the departmental norm (i.e., this is the way our department teaches these classes) OR describes other more subtle supports such as having been positively influenced by a local colleague that had taught with PI, tracking or following an instructor that taught the course with PI and developed PI materials that were shared with other instructors (i.e., the person that taught this class before me did something innovative and I just tried to do what they did), working with a smaller subgroup of faculty to determine what to change in their classes. This code also includes department dedication of funds to new tables, equipment, workshops, or clickers, which was perceived as support for PI by faculty.

Dissatisfaction with lecture: Explicit discussion of how traditional lecture does not work or is not effective, reflecting a dissatisfaction with past practices or traditional lecture specifically. These comments imply that anything is better than traditional lecture, so in this sense PI is good because it is not traditional lecture.

Easy transition from traditional lecture: Explicit discussion about how he or she could start with small changes to what he or she was already doing. The interviewee might also mention that PI was easily integrated into the previously prepared lecture or lecture materials. The general sentiment captured here is adopting PI meant that the faculty could use the innovation, but not "throw the baby out with the bath water."

Encourages depth of understanding: PI allows students to better learn what is covered or gets students to really understand a smaller number of things. Some faculty say that a positive aspect of PI is that it allows the instructor to focus more deeply (reflecting a "less is more" approach to the organization of content).

Evidence of effectiveness, data: Explicit discussion of compelling data that shows that PI (or interactive engagement) improves student learning outcomes. The interviewee comments may be fairly vague citing research or evidence showing that "it works" without going into specifics. Under this code, by "data" we mean summative assessments such as FMCE/FCI/BEMA/CSEM, etc. [17,55,56] although the interviewee may not typically be this specific. The data could be locally collected and shared, or published data such as Mazur's [3] or Hake's [57].

Evidence of effective, opinion of valued other: Explicit discussion about how PI or using PI is a good thing because another respected physicist or physics colleague advocated or advocates for PI or using PI. This code captures esteemed or valued others that have a positive view of PI that is compelling to other faculty as a reason to try or to continue to use PI. This could include the opinion of PER experts, respected professional physicists, or the personal opinion of a friend.

Evidence of effectiveness, personal experience: Explicit discussion of their own positive experiences using PI and (or) seeing PI work (in the context of the interviewee as an educator, as an observer of another educator using PI of PI elements, or as a student themselves when their teacher was using PI or PI elements). These positive evaluations of PI "in action" can be based on a variety of assessment sources, such as moment-to-moment classroom interactions, students' in-class questions, exam performance, etc.

Forces more students to participate: PI helps to get more (a higher percentage of) students to participate in class or gets others involved in class that otherwise would not be.

Gets students active: PI seems like a good idea because it gets students talking or solving problems in class. This will include vague comments about getting students to be active or engaged in class.

Gets students working together: PI seems like a good idea because it gets students working with one another in class.

Improves the atmosphere in the class: PI helps to make the class more friendly, collegial, or relaxed, or how PI helps students build their own ideas without deferring to authority.

Intuitively makes sense to me: PI seems like a good idea in general. If the interviewee is more specific, we coded the sentiment under more specific codes.

Maintains anonymity: PI is good for allowing students to participate without revealing their identity. Faculty may comment on how PI reduced the barrier for participating since their entire class of peers will not be aware of their answers or thinking.

Matches my personality: PI fits with the instructor's personality or style.

Provides feedback to instructor: PI provides the faculty access to the level of student understanding in the room. Usually faculty talk about using PI activities to decide if they can reasonably move on from a topic or if additional work is needed on that topic. Other comments come up in the context of instructor feedback around the timeliness of this feedback within the PI method.

Provides feedback to students: PI provides students with information about their level of understanding. Faculty may talk about giving students time to ask questions or address their confusions, or they may talk about alerting students to their misunderstanding so that they can work on things outside of class or come to office hours. Other comments come up in the context of feedback to students around the timeliness or immediacy of this feedback within PI.

Students learn by giving explanations to peers: PI is good because students learn by giving explanations or having to express their ideas in words to another person. 


\section{APPENDIX B}

Table VII below summarizes our code definitions for the reasons faculty give for NOT aligning their instruction with Peer Instruction (or elements of PI).

TABLE VII. Definitions of perceived constraints of PI use codes (alphabetically).

Perceived constraints of PI codes and associated definitions

Content coverage concerns based on personal commitment: PI problematically requires reducing the content covered in the course (which is of personal concern).

Content coverage concerns based on external requirements: PI requires reducing the content covered in the course which is problematic due to external content coverage requirements such as the MCATs, university transfer-credit expectations, teacher certification exams, etc. (However, this will NOT include departmental expectations of content coverage).

Content coverage concerns based on institutional expectations: PI requires reducing the content covered in the course which is problematic due to departmental content coverage expectations or other institutional constraints within the university or college including interdepartmental negotiations about what physics is required for other majors, credit hours of physics available to other majors, etc.

Current practices are effective: PI is not needed or necessary, since the status quo is working fine [for the instructor and (or) their students].

Data NOT convincing: PI not worth using because of skepticism regarding the evidence of the strategy's efficacy (i.e., the data on PI effectiveness are not compelling or believable).

Student shortcomings make them unable to learn through PI: Students lack knowledge or skills to effectively learn within PI activities. This may include content (wrong physics ideas), pedagogical (students' cannot explain things well), group dynamics (do not know how to debate or disagree with each other), or metaskills (students will just flounder and not get anywhere). Students are blamed for the ineffectiveness or potential ineffectiveness of PI (or PI features).

Difficulty getting student buy-in: Instructor describes difficulties in getting student buy-in or taking particular actions in the course to build student buy-in for PI activities. This captures all issues related to how to get student buy-in and problems with active student resistance.

Difficulty getting students engaged: Instructor explicitly discusses difficulties in getting students engaged or involved in PI activities (this could be vague, or more specifically about difficulties getting students to work together). This captures all issues related to how to get students to participate in PI activities.

In personal experience it did NOT work: Instructor describes that in his or her experience PI does NOT work. These negative evaluations are based on personal experiences trying to use or implement PI.

Intuitively do not think that PI will work: Instructor explicitly discusses how they do not believe that PI (or PI element) will work (either in the classroom in practice or for supporting student learning). This, however, excludes elements that are more explicitly "structural," which are coded explicitly under structural subcodes. This includes faculty talking about worries or fears that they have about using PI which are not based on actual experience trying to use PI. Under this code, we include all comments about how PI counters faculty's intuitions about what students need or what works in the classroom.

Mismatch between PI and course goals: PI does not meet his or her goals for their introductory physics course. Sometimes this will come up with regard to the "conceptual" emphasis of PI which is perceived to sit in tension with a computational (quantitative) or problemsolving emphasis in introductory physics.

Mismatch with personality: PI does NOT fit an instructor's personality or teaching style. This includes comments that compare the interviewee to other educators that "have an easier time" doing X, Y, Z ... when these comparisons between different faculty are being made as if they were characteristics or attributes of people will all be considered under "personality."

Requires time and energy to change: Instructor describes it being difficult to figure out something new (could be prior to a semester or in the day-to-day of running a course). Instructor describes the time and energy it takes for faculty to learn or change. Some faculty say "I don't have a concrete idea of what this would look like in the classroom" or "I don't have training in this" or "PI is not what I am used to doing." It takes time (work and energy) to combine something new into your course (or to combine with other RBIS).

Structural, assessment barriers: Instructor does not think that PI (or elements of PI) will work for them due to faculty assessment procedures. This includes all ramifications about employment such as tenure, retention, firing, forced retirement, advancement, or promotion. Other minor ideas that come up include lack of acknowledgement or reward for teaching changes or administrative pressures concerning enrollment and the number of majors.

Structural, class size: Interviewee does not think that PI (or elements of PI) will work for them due to the size of classes that they teach (this may be because the class is perceived to be too large for PI or that the class is too small for PI).

Structural, course schedule structure: Interviewee does not think that PI (or elements of PI) will work for them due to the registrar's imposed time structure of the course. This includes complaints about the length of class periods, complaints about missing small-sized recitation section meetings, and available credit hours available to various majors.

Structural, lack of appropriate classroom: Interviewee does not think that PI (or elements of PI) will work for them due to the room that they teach in.

(Table continued) 
TABLE VII. (Continued)

Perceived constraints of PI codes and associated definitions

Structural, lack of resources: Interviewee does not think that PI (or elements of PI) will work for them due to lack of or limited access to PRS equipment, budget cuts such as salary freezes or furlough days, whiteboards, incompatible laptops, limited access to physics teaching literature, lack of support for attending teaching conferences, lack of assistance staff such as TAs to support monitoring group work.

Structural, need to coordinate with other instructors: Interviewee does not think that PI (or elements of PI) will work for them due to the need to coordinate with others in the department in order to make changes like this. This code includes having multiple instructors assigned to teach different sections of the same course, or constraints about having common exams.

Structural, overloaded with duties: Interviewee does not think that PI (or elements of PI) will work for them due to issues with short staffing that may be responsible for higher teaching loads, or other job responsibilities that tax the time commitments of faculty (note: research only rarely comes up here).

Trouble finding good questions: Interviewee explicitly comments on struggling to find good PI questions (often describes using PI questions other than the ones that Mazur wrote). This may include writing his or her own questions or drawing from other sources such as textbooks, online banks of questions, or locally available materials from other colleagues.

\section{APPENDIX C}

Table VIII lists the prevalence of perceived affordance and perceived constraint coding categories by researcher-assigned PI user implementation group.

TABLE VIII. Prevalence of perceived affordances and constraints by user group (for those with meaningful differences). High users $(N=7)$, mixed users $(N=18)$, nonusers $(N=10)$. When comparing mixed users and nonusers, a $30 \%$ difference will be considered potentially meaningful since each group has 10 or more people in it. However, when comparing high users to either nonusers or mixed users we will only consider differences of $43 \%(N=3$ out of 7$)$ to be a potentially meaningful result.

\begin{tabular}{|c|c|c|c|c|}
\hline & & $\%$ of high users & $\%$ of mixed users & $\%$ of nonusers \\
\hline \multirow[t]{10}{*}{ Affordances } & \multirow[t]{2}{*}{ Dissatisfaction with lecture ${ }^{a, b}$} & 86 & 78 & 0 \\
\hline & & $(6 / 7)$ & $(14 / 18)$ & $(0 / 10)$ \\
\hline & \multirow[t]{2}{*}{ Gets students active ${ }^{b}$} & 43 & 67 & 20 \\
\hline & & $(3 / 7)$ & $(12 / 18)$ & $(2 / 10)$ \\
\hline & \multirow[t]{2}{*}{ Intuitively makes sense to me ${ }^{a, b}$} & 57 & 44 & 10 \\
\hline & & $(4 / 7)$ & $(8 / 18)$ & $(1 / 10)$ \\
\hline & \multirow[t]{2}{*}{ Forces more students to participate ${ }^{\mathrm{a}, \mathrm{c}}$} & 71 & 11 & 0 \\
\hline & & $(5 / 7)$ & $(2 / 18)$ & $(0 / 10)$ \\
\hline & \multirow[t]{2}{*}{ Easy transition from traditional lecture ${ }^{a}$} & 43 & 17 & 0 \\
\hline & & $(3 / 7)$ & $(3 / 18)$ & $(0 / 10)$ \\
\hline \multirow[t]{14}{*}{ Constraints } & \multirow[t]{2}{*}{ Requires time and energy to change ${ }^{a, b}$} & 14 & 56 & 90 \\
\hline & & $(1 / 7)$ & $(10 / 18)$ & $(9 / 10)$ \\
\hline & \multirow[t]{2}{*}{ Difficulty getting students engaged ${ }^{a, c}$} & 100 & 39 & 30 \\
\hline & & $(7 / 7)$ & $(7 / 18)$ & $(3 / 10)$ \\
\hline & \multirow[t]{2}{*}{ Student shortcomings make them unable to learn through PI ${ }^{b}$} & 29 & 28 & 60 \\
\hline & & $(2 / 7)$ & $(5 / 18)$ & $(6 / 10)$ \\
\hline & \multirow[t]{2}{*}{ Structural, class size ${ }^{\mathrm{a}}$} & 0 & 33 & 50 \\
\hline & & $(0 / 7)$ & $(6 / 18)$ & $(5 / 10)$ \\
\hline & \multirow[t]{2}{*}{ Current practices are effective ${ }^{a}$} & 0 & 22 & 50 \\
\hline & & $(0 / 7)$ & $(4 / 18)$ & $(5 / 10)$ \\
\hline & \multirow[t]{2}{*}{ Content coverage concerns based on external requirements ${ }^{a, b}$} & 0 & 17 & 50 \\
\hline & & $(0 / 7)$ & $(3 / 18)$ & $(5 / 10)$ \\
\hline & \multirow[t]{2}{*}{ Mismatch with personality ${ }^{\mathrm{b}}$} & 0 & 0 & 40 \\
\hline & & $(0 / 7)$ & $(0 / 18)$ & $(4 / 10)$ \\
\hline
\end{tabular}

${ }^{\mathrm{a}}$ Meaningful difference between high users and nonusers.

${ }^{\mathrm{b}}$ Meaningful difference between mixed users and nonusers.

${ }^{\mathrm{c}}$ Meaningful difference between high users and mixed users. 
[1] C. Henderson, M. Dancy, and M. Niewiadomska-Bugaj, Use of research-based instructional strategies in introductory physics: Where do faculty leave the innovationdecision process?, Phys. Rev. ST Phys. Educ. Res. 8, 020104 (2012)

[2] C. H. Crouch, J. Watkins, A. P. Fagen, and E. Mazur, Peer Instruction: Engaging students one-on-one, all at once, in Research-Based Reform of University Physics, Reviews in $P E R$, edited by E. F. Redish and P. J. Cooney, Vol 1, http://www.compadre.org/PER/document/ServeFile.cfm? $\mathrm{ID}=4990 \&$ DocID $=241$.

[3] A. P. Fagen, C. H. Crouch, and E. Mazur, Peer Instruction: Results from a range of classrooms, Phys. Teach. 40, 206 (2002).

[4] E. Mazur, Peer Instruction: A User's Manual (Prentice Hall, Upper Saddle River, NJ, 1997).

[5] E. Mazur and C. H. Crouch, Peer Instruction: Ten years of experience and results, Am. J. Phys. 69, 970 (2001).

[6] E. Mazur, Farewell, Lecture?, Science 323, 50 (2009).

[7] C. Henderson and M. H. Dancy, The impact of physics education research on the teaching of introductory quantitative physics in the United States, Phys. Rev. ST Phys. Educ. Res. 5, 020107 (2009).

[8] M. H. Dancy and C. Henderson, Pedagogical practices and instructional change of physics faculty, Am. J. Phys. 78, 1056 (2010).

[9] M. Lorenzo, C. H. Crouch, and E. Mazur, Reducing the gender gap in the physics classroom, Am. J. Phys. 74, 118 (2006).

[10] N. Lasry, E. Mazur, and J. Watkins, Peer Instruction: From Harvard to the two-year college, Am. J. Phys. 76, 1066 (2008).

[11] T. Gok, The Impact of Peer Instruction on college students' beliefs about physics and conceptual understanding of electricity and magnetism, Int. J. Sci. Math. Educ. 10, 417 (2012).

[12] S. Freeman, D. Haak, and A. P. Wenderoth, Increased course structure improves performance in introductory biology, CBE Life Sci. Educ. 10, 175 (2011).

[13] M. K. Smith, W. B. Wood, K. Krauter, and J. K. Knight, Combining peer discussion with instructor explanation increases student learning from in-class concept questions, CBE Life Sci. Educ. 10, 55 (2011).

[14] M. A. Ruiz-Primo, D. Briggs, H. Iverson, R. Talbot, and L. A. Shepard, Impact of undergraduate science course innovations on learning, Science 331, 1269 (2011).

[15] J. D. Chase and E. G. Okie, in Proceedings of the ThirtyFirst SIGCSE Technical Symposium on Computer Science Education, 2000 (SIGCSE 2000) (ACM, New York, 2000), Vol. 32, pp. 372-376.

[16] M. Borrego, J. E. Froyd, and T. S. Hall, Diffusion of engineering education innovations: A survey of awareness and adoption rates in U.S. engineering departments, J. Eng. Educ. 99, 185 (2010).

[17] A. Madsen, S. B. Mckagan, and E. C. Sayre, Gender gap on concept inventories in physics: What is consistent, what is inconsistent, and what factors influence the gap?, Phys. Rev. ST Phys. Educ. Res. 9, 020121 (2013).
[18] L. E. Kost, S. J. Pollock, and N. D. Finkelstein, Characterizing the gender gap in introductory physics, Phys. Rev. ST Phys. Educ. Res. 5, 010101 (2009).

[19] E. M. Rogers, Diffusion of Innovations, 4th ed. (Free Press, New York, 1995).

[20] C. Henderson and M.H. Dancy, Physics faculty and educational researchers: Divergent expectations as barriers to the diffusion of innovations, Am. J. Phys. 76, 79 (2008).

[21] C. Henderson, The challenges of instructional change under the best of circumstances: A case study of one college physics instructor, Am. J. Phys. 73, 778 (2005).

[22] S. E. Anderson, Understanding teacher change: Revisiting the concerns based adoption model, Curriculum Inquiry 27, 331 (1997).

[23] G. E. Hall and S. M. Hord, Implementing Change: Patterns, Principles, and Potholes (Allyn \& Bacon, Needham Heights, MA, 2001).

[24] D. L. Horsley and S. Loucks-Horsley, CBAM brings order to the tornado of change, J. Staff Dev. 19, 17 (1998).

[25] M. H. Dancy, C. R. Henderson, and C. Turpen, How faculty learn about and implement research-based instructional strategies: The case of Peer Instruction (to be published).

[26] M. H. Dancy, C. Henderson, and C. Turpen, How faculty learn about and implement research-based instructional strategies: The case of Peer Instruction (to be published).

[27] J. Foertsch, S. B. Millar, L. Squire, and R. Gunter, Persuading Professors: A Study of the Dissemination of Educational Reform in Research Institutions (University of Wisconsin-Madison, LEAD Center, Madison, WI, 1997).

[28] A. Ho, D. Watkins, and M. Kelly, The conceptual change approach to improving teaching and learning: An evaluation of a Hong Kong staff development programme, Higher Educ. 42, 143 (2001).

[29] J. B. Ellsworth, Surviving Change: A Survey of Educational Change Models (Office of Educational Research and Improvement, Washington, DC, 2000).

[30] M. Prosser and K. Trigwell, Understanding Learning and Teaching: The Experience in Higher Education (St. Edmundsbury Press, Great Britain, 1999).

[31] C. Henderson, A. Beach, and N. Finkelstein, Facilitating change in undergraduate STEM instructional practices: An analytic review of the literature, J. Res. Sci. Teach. 48, 952 (2011).

[32] C. Turpen and N.D. Finkelstein, Not all interactive engagement is the same: Variations in physics professors' implementation of Peer Instruction, Phys. Rev. ST Phys. Educ. Res. 5, 020101 (2009).

[33] C. Henderson and M. H. Dancy, Barriers to the use of research-based instructional strategies: The influence of both individual and situational characteristics, Phys. Rev. ST Phys. Educ. Res. 3, 020102 (2007).

[34] M. H. Dancy, C. Turpen, and C. Henderson, in Proceedings of the 2010 AAPT Physics Education Research Conference, edited by C. Singh, M. Sabella, and S. Rebello (American Institute of Physics, Melville, NY, 2010), pp. 117-120.

[35] K. Foote, X. Neumeyer, C. Henderson, M. H. Dancy, and R. J. Beichner, Diffusion of research-based instructional 
strategies: The case of SCALE-UP, Int. J. STEM Educ. 1, 10 (2010).

[36] M. Borrego, S. Cutler, M. Prince, C. Henderson, and J. E. Froyd, Fidelity of implementation of research-based instructional strategies (RBIS) in engineering science courses, J. Eng. Educ. 102, 394 (2013).

[37] N. Finkelstein, Learning physics in context: A study of student learning about electricity and magnetism, Int. J. Sci. Educ. 27, 1187 (2005).

[38] L. R. Lattuca, Influences on engineering faculty members' decisions about educational innovations: A systems view of curricular and instructional change (to be published), https://www.nae.edu/File.aspx?id=36674.

[39] L. R. Lattuca and J.S. Stark, Shaping the College Curriculum: Academic Plans in Context, 2nd ed. (Jossey-Bass, San Francisco, 2009).

[40] J. J. Gibson, in Perceiving, Acting, and Knowing: Toward an Ecological Psychology, edited by R. Shaw and J. Bransford (Lawrence Erlbaum Associates, Hillsdale, NJ, 1977), pp. ix, 492.

[41] J.J. Gibson, The Ecological Approach to Visual Perception (Houghton Mifflin, Boston, 1979).

[42] D. A. Norman, The Design of Everyday Things (Basic Books, New York, 1988).

[43] J. P. Gee, in Assessment, Equity, and Opportunity to Learn, edited by P. A. Moss, D. C. Pullin, J. P. Gee, E. H. Haertel, and L. J. Young (Cambridge University Press, New York, 2008), Chap. 4, pp. 76-108.

[44] National Research Council, Promising Practices in Undergraduate Science, Technology, Engineering, and Mathematics Education: Summary of Two Workshops (National Academies Press, Washington, DC, 2011).

[45] D. W. Sunal, J. Hodges, C. S. Sunal, K. W. Whitaker, L. M. Freeman, L. Edwards, R. A. Johnston, and M. Odell, Teaching science in higher education: Faculty professional development and barriers to change, School Sci. Math. 101, 246 (2001).

[46] National Research Council Committee on Undergraduate Physics Education Research and Implementation, Adapting to a Changing World: Challenges and
Opportunities in Undergraduate Physics Education (National Academies, Washington, DC, 2013).

[47] National Research Council, Discipline-Based Education Research: Understanding and Improving Learning in Undergraduate Science and Engineering (National Academies Press, Washington, DC, 2012).

[48] J. Handelsman, D. Ebert-May, R. J. Beichner, P. Bruns, A. Chang, R. Dehaan, J. Gentile, S. Lauffer, J. Stewart, S. M. Tilghman, and W. B. Wood, Education: Scientific teaching, Science 304, 521 (2004).

[49] R. Graham, Achieving Excellence in Engineering Education: The Ingredients of Successful Change (Royal Academy of Engineering, London, 2012).

[50] J. Michael, Faculty perceptions about barriers to active learning, Coll. Teach. 55, 42 (2007).

[51] C. Henderson, Promoting instructional change in new faculty: An evaluation of the Physics and Astronomy New Faculty Workshop, Am. J. Phys. 76, 179 (2008).

[52] M. Windschitl, Framing constructivism in practice as the negotiation of dilemmas: An analysis of the conceptual, pedagogical, cultural, and political challenges facing teachers, Rev. Educ. Res. 72, 131 (2002).

[53] T. Greenhalgh, G. Robert, F. Macfarlane, P. Bate, and O. Kyriakidou, Diffusion of innovations in service organizations: Systematic review and recommendations, Milbank Q. 82, 581 (2004).

[54] J. W. Dearing and M. W. Kreuter, Designing for diffusion: How can we increase uptake of cancer communication innovations?, Patient Educ. Couns. 81, S100 (2010).

[55] J. C. Libarkin, in Proceedings of the National Academies of Science Workshop on Linking Evidence and Promising Practices in STEM Undergraduate Education (National Academies Press, Washington, DC, 2008).

[56] J. Richardson, Inventions and Impact (AAAS, Washington, DC, 2004), pp. 19-25.

[57] R. R. Hake, Interactive-engagement vs. traditional methods: A six-thousand-student survey of mechanics test data for introductory physics courses, Am. J. Phys. 66, 64 (1998). 